\title{
The Syntactic Position of Negative Markers in Idoma and Tiv: A Deviation from Language Universal Validity
}

\author{
Issa Olarongbe Sanusi \& Lydia Damilola Oyewole \\ University of Ilorin, Nigeria
}

\begin{abstract}
Syntacticians and typologists have carried out a cross-linguistic study of the syntactic position of the negative marker with respect to the verb in a given sentence (Greenberg 1966 and Dryer 1988). The objective of this study is to carry out a comparative study of
\end{abstract}

Issa O. Sanusi (First \& Corresponding Author)

Associate Professor, Department of Linguistics and Nigerian Languages, University of Ilorin, Nigeria

Email: sanusissa2@yahoo.com

Lydia D. Oyewole (Co-author)

Researcher, Department of Linguistics and Nigerian Languages, University of Ilorin, Nigeria Email: damsly25@gmail.com

Received 9 January, 2019; Revised 2 March, 2019; Accepted 11 March, 2019

Copyright (C) 2019 Language Research Institute, Sejong University Journal of Universal Language is an Open Access Journal. All articles are distributed online under the terms of the Creative Commons Attribution Non-Commercial License (http://creativecommons.org/licenses/by-nc/3.0) which permits unrestricted non-commercial use, distribution, and reproduction in any medium, provided the original work is properly cited. 
78 The Syntactic Position of Negative Markers in Idoma and Tiv:

the negative marking strategies in both Idoma and Tiv languages, spoken in Benue State, Nigeria. Given the fact that the two languages belong to the same genetic family (Benue-Congo) and share the same basic word order (subject, S; object, O; verb ,V); the study is intended to find out the extent to which the negative marking strategies in the two languages conform to the assumption under language universals. The assumption is that there is an overall tendency for the negative marker to precede the main verb in SVO languages. That is, a location between the subject and the verb. Since none of the two writers speaks any of the two languages, data were collected through interview method. And the frame technique method was adopted in presenting structured grammatical sentences in English to native speakers of the two languages to translate to both Idoma and Tiv. The Principles and Parameters approach was employed for our analysis in this study. Our findings revealed that what obtains in both Idoma and Tiv negative constructions is contrary to the assumption under language universals. Instead of preceding the main verb, the negative markers occur at the sentence-final position, in each of the two languages. Notwithstanding the deviation from the language universal validity, we have discovered a high degree of similarities in the syntactic behaviour of negative markers in both Idoma and Tiv languages.

Keywords: negative marker, syntactic position, language universal, Idoma, Tiv

\section{Introduction}

Negation is a syntactic phenomenon that has generated a lot of investigations in the field of linguistics. Efforts have been made by experts to examine the syntactic positions occupied by the 'negator' in a given grammatical sentence. The objective of this study is to examine the similarities and differences between the negative marking strategies in both Idoma and Tiv languages spoken in Benue State, Nigeria. The main purpose of the study is to find out whether or not 
their common genetic relationship, being members of Benue-Congo, reflects the language universal validity about negative marking. The investigation was carried out through an examination of both sentence and constituent negation in the two languages.

\section{Idoma: The Language and Its Speakers}

Armstrong (1955: 91) submits that the Idoma people occupy the area from Keana through Doma and Agatu districts of Lafia and Nasarawa and the Nkum in Ogoja area of the present Cross River State. Erim (1981: 3) also states that the Idoma lived within the ancient Kwararafa confederacy before AD 1800 and that they were Jukun or Jukun-related in origin.

However, many Idoma kindred, trace their origin to an ancestral homeland called Apa, North-East of the present-day Idomaland. The historical Apa was part of the ancient Kwararafa Kingdom (Okolofa Kingdom), a confederacy of several people. According to Umaru (2016: 3), "Idoma is the language spoken by the Idoma people who are predominantly found in Benue State with clusters of them found among other ethnic groups, especially Afoand Alago in Nasarawa State and Yala."

Other linguistic groups that share close relationship with the Idoma of Benue State are: the Gede in Federal Capital Territory, Abuja, Afa, and Alago in Nasarawa State, Igala, and Ebira in Kogi State, Akweya and Etulo in Benue State, as well as Jukun in Taraba State. These languages and Idoma have a high degree of mutual intelligibility due to their historical and genetic commonalities. The Idoma language belongs to the Idomoid language family, a member of the Benue-Congo language family (see Figure 1). 


\subsection{Tiv: The Language and Its Speakers}

According to Gbor (1978: 9-12), the Tiv people have Bantu origin. He maintains that the migrant Tiv coming from their original homeland in Congo passed through Swem where they settled for sometime before arriving at their present-day location at the middle belt in Nigeria. Continuing their journey down from the Swem hills, the migrant Tiv came in contact with a new group of people called the Chamba. It was while they were staying with these people that the Tiv learned to develop a relatively advanced culture. This was particularly in the areas of food crops, hunting methods, marriage by bride price, and form of chieftaincy tradition.

However, the Tiv did not stay for too long with the Chamba. A war broke out between these two groups in which the Tiv suffered defeat. Having been defeated and driven away by the Chamba, they headed to their present-day habitat in the middle belt. As noted by Akiga (1965: 13), the area covered by the Tiv in the middle belt region is the "pleasant savannah country to the south of the River Benue and a narrow strip along its north bank". Atel (2004: 7) reports that Tivland is surrounded by neighbouring ethnic groups such as the Udam who are made up of a collection of ethnic groups on the south, the Jukum, the Chamba, and the Mumuye on the East, the Alago, Angwe, and Koro on the North, and the Idoma, Igede and Igala on the West. Genetically, Tiv belongs to the Bantoid language family, a sub-family of Benue-Congo language family.

The language family tree showing the genetic classification of Idoma and Tiv is shown in (Figure 1). 
Figure 1. The Idoma and Tiv Language Family Tree (Blench \& Mallam 2004, adapted from Umaru (2016: 3))

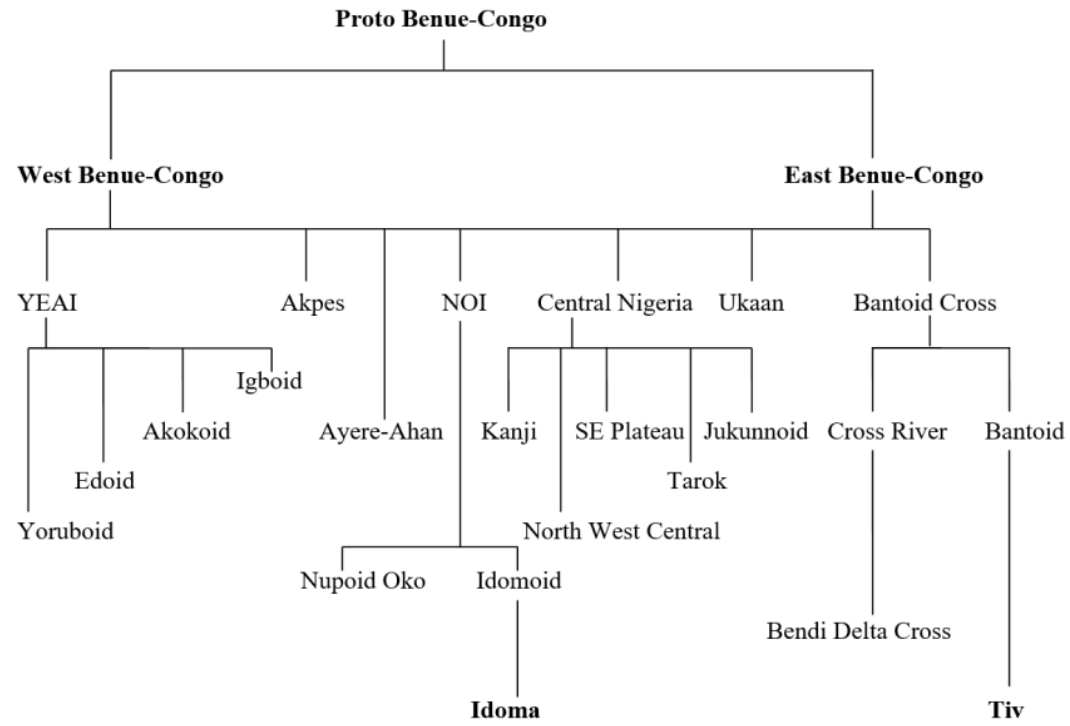

\subsection{Statement of the Problem}

This study is intended to find out the extent to which the negative marking strategies in the two languages under study conform to the assumption under language universals. The assumption is that there is an overall tendency for the negative marker to precede the main verb in SVO languages.

\subsection{Theoretical Framework}

The theoretical framework adopted for our analysis in this work is Government and Binding (GB) theory, otherwise known as Principles 
82 The Syntactic Position of Negative Markers in Idoma and Tiv:

and Parameters approach. Haegeman (1991: 13) considers GB as a theory of universal grammar (UG), consisting of all the principles and parameters that are common to all natural languages. Also, Sanusi (2017: 21) defines GB as a "modular deductive theory of UG, which posits multiple levels of representation related by the transformational rule (Move Alpha)".

According to Cook \& Newson (2007: 3), "This model claims that human languages consisted of principles that were the same for any grammar and parameters that allow grammars to vary in limited ways". Also, Sanusi (2017: 21) explains that GB theory greatly eliminates proliferation of transformational rules like: passive, affixhopping, verb-number agreement, question formation, equi-NP deletion, raising, permutation, insertion, etc.

In GB theory, the grammar is a continuous interaction between components and sub-theories embodying different principles and parameters. Furthermore, Horrocks (1987: 29) explains that, the core grammar of a given language is derived from the interaction of subtheories of UG. These sub-theories are inter-related that each of them can account for grammaticality or ungrammaticality of any sentence.

\section{Defining Language Universals}

In his attempt to define the concept of language universals, Pericliev (2018: 34) traced the origin of the idea of language universals to Greenberg (1966). According to him, “A language universal is usually defined as a property that is valid for (or most) of the languages of the world." In other words, the idea of language universals connotes what is common to all human languages. Furthermore, while considering the relationship between typological classification of languages and language universals, Malmkjaer 
(2002), makes the following remarks:

Some language universals are features present in all or an overwhelming majority of languages. Other universals are implicational: they state that if feature $\mathrm{x}$ is present in a language, then (it is highly likely that) feature y will also be present in that language.

This means that languages are typologized on the basis of the order in which Subject (S), Object (O), and Verb (V) typically occur in the simple sentence of the language, generally referred to as 'Word Order' typology. Greenberg (1966: 76) identifies the first three word orders (i.e., SVO, SOV and VSO) as the most commonly found among human languages. Dryer (1988: 93) in his study of the placement of negative marker in relation to the first three word order commonly found among languages (i.e., SVO, SOV, and VSO), he submits that SVO languages are most commonly SNegVO. Therefore, based on the 'Word Order' typology English language as an SVO language places its negative marker pre-verbally occurring after the first auxiliary in a verb phrase. The Yorùbá language, as an SVO language, also places its negative marker pre-verbally occurring before the main verb of the sentence. However, both Idoma and Tiv, which are also SVO languages, place their negative markers post-verbally, occurring at the sentence final position. This is contrary to the claim made under language universals that negative markers in SVO languages occur pre-verbally at the syntactic position between the subject and the verb.

\subsection{Defining Negation}

According to Jackson (2007: 43), "negation is the expression of the denial or reverse of the state of affairs". In English, the most 
common negative expression is the particle 'not' which is positioned after the first auxiliary in a verb phrase and often contrast (may not come, hasn't been seen).' Negation may, however, be expressed in a variety of ways (No dogs allowed; 'You must never say that', 'she can be so uncaring'). Crystal (2008: 323) also submits that "negation is a process or construction in grammatical and semantic analysis which typically expresses the contradiction of some or all of a sentence's meaning". "Negation is a process of construction in grammatical and semantic analysis, which typically expresses the contradiction of some or all of the meaning of a sentence" (Lyons 1977: 75). Following Watter (2000), there are two different kinds of negation;

(i) Sentence negation: in this case, the sentence as a whole may be negated.

(ii) Constituent negation: here, a particular constituent of the sentence may be negated.

\subsection{The Existence of Negation in Many Natural Languages}

The study of negation has featured for centuries in the study of eminent logicians, philosophers, linguists and psychologists. As a result, many features of negation have been collected and investigated in many natural languages. This, therefore, provides the basis for the present study.

Languages differ as to the particular syntactic position which the negative markers assume in any given grammatical sentence. Syntacticians and typologists have carried out a cross-linguistic study of the syntactic position of the negative marker with respect to the verb in a given sentence. Greenberg (1966) and Dryer (1988) are well-known examples of such studies. They claim that there is an overall tendency for the negative marker to precede the verb. 
Jespersen, in his study of the patterns of pre-verbal/post-verbal negation, identifies a strong tendency "to place the negative first, or at any rate as soon as possible, very often immediately before the particular word to be negated" (Jespersen 1917: 4).

Also, Dryer (1988: 93) presents a study of the placement of negative marker in relation to the three main clausal elements of subject (S), object (O) and verb (V) in a worldwide sample of 345 languages. He submits that SVO languages are commonly SNegVO. In other word, SVO languages place their negative markers preverbally, occurring at the position before the main verb. This section discusses the various syntactic positions occupied by the negative markers in some natural languages with SVO basic word order, similar to Idoma and Tiv languages.

\subsection{Negation in English}

According to Jackson (2007: 43), the most common negative expression in English is the particle 'not' which is positioned after the first auxiliary in a verb phrase. Haegeman (1995: 28) submits that the negative markers in English could occur at any of the following syntactic locations:

(i) within the auxiliary in sentences

(ii) as part of the subject nominal

(iii) as part of adverb of place

(iv) within a prepositional modifier

(v) within infinitival complements

The occurrence of negative marker in each of the above mentioned syntactic positions in English can be exemplified as in (1). 
(1) Affirmative and Negative Sentences in English

\section{a. Affirmative}

(i) Olu came.

(ii) Jean made the child to eat the food.

(iii) John ate rice.

(iv) Jane is a student.

(v) Peter cooked the food. b. Negative

(i) Olu did not come.

(ii) Jean made the child not to eat the food.

(iii) John did not eat rice.

(iv) Jane is not a student.

(v) Peter did not cook the food.

In the above examples in English language, the negative marker 'not' occurs after the first auxiliary and within the infinitival complement. English exemplifies a complex situation in which negation follows the auxiliary, but precedes the main verb. This motivates the construction of $d o$-support in sentences where auxiliaries are not present.

\subsection{Negation in Yorùbá}

Yorùbá belongs to the Kwa group of the Benue-Congo language family. It is a language spoken in the South-western part of Nigeria and some parts of African continent. The language has an SVO word order and attests negation. Like English, Yorùbá places its negative marker pre-verbally occurring before the main verb in any grammatical sentence. This shows that Yorùbá conforms to the assumption that SVO languages place negative marker pre-verbally.

This can be exemplified as shown in (2) below.

(2) Affirmative and Negative Sentences in Yorùbá

\section{a. Affirmative}

\begin{tabular}{|c|c|}
\hline Olú & jẹ \\
\hline Olú & eat \\
\hline $\mathrm{S}$ & $\mathrm{V}$ \\
\hline
\end{tabular}

b. Negative

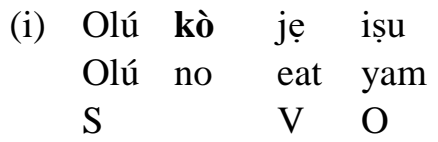


'Olú ate yam.'

(ii) Shọlá ra bàtà Shọlá buy shoe S V O 'Shọlá bought shoes.'

(iii) Bímpé pọn omi Bímpé fetch water S V O 'Bímpé fetched water.'

(iv) Tádé gbá bọọlù

Tádé play ball

$\mathrm{S} \quad \mathrm{V} \mathrm{O}$

'Tádé played the ball.'

(v) Àbíké ra aṣo Àbíké buy cloth $\mathrm{S} \quad \mathrm{V} \mathrm{O}$ 'Àbíké bought cloth.'
'Olú did not eat yam.'

(ii) Shọlá kò ra bàtà Shọlá not buy shoe S V O 'Shọlá did not buy shoes.'

(iii) Bímpé kò pon omi Bímpé not fetch water S $\quad \mathrm{V} \quad \mathrm{O}$ 'Bímpé did not fetch water.'

(iv) Tádé kò gbá bọoụù Tádé not play ball S $\quad \mathrm{V} \quad \mathrm{O}$ 'Tádé did not play ball.'

(v) Àbíké kò ra aṣo Àbíké not buy cloth S $\quad \mathrm{V} O$ 'Àbíké did not buy clothes.'

In the above examples in Yorùbá, the negative marker kò is placed pre-verbally, next to the main verb. In other words, the negative marker occurs before the main verb.

\section{Negation in Idoma}

In Idoma, the negative marker nó occurs at the sentence final position in any given negative construction. We can therefore say that Idoma negative marker occurs post-verbally, as against the universal 
88 The Syntactic Position of Negative Markers in Idoma and Tiv:

based hypothesis of pre-verbal occurrence between the subject position and the inflected $\mathrm{V}$. This can be exemplified with the data in (5) below.

(3) Sentence Negation: Affirmative/Negative Sentences in Idoma

a. Affirmative

(i) Peter lo dule

Peter eat food

S V O

'Peter ate the food.' b. Negative

(i) Peter lo dule a nó Peter eat food the Neg $\mathrm{S} \quad \mathrm{V} \quad \mathrm{O}$ 'Peter did not eat the food.'

(ii) Èbègényen gbè nehì fish is big S V Adj

'The fish is big.'

(ii) Èbègényen gbè nehì nǒ fish is big $\mathrm{Neg}$ S V Adj

'The fish is not big.'

(iii) éné hògì kappa mother cook rice S $\quad \mathrm{V} \quad \mathrm{O}$

'Mother cooked rice.'

(iv) Bright ńmé eyin Bright fetch water S $\quad \mathrm{V} \quad \mathrm{O}$

'Bright fetched water.'

(iii) Éné hògì kappa a nǒ mother cook rice the $\mathrm{Neg}$ S $\quad \mathrm{V} \quad \mathrm{O}$ 'Mother did not cook the rice.'

(iv) Bright ńmé eyin a nǒ Bright fetch water the Neg S $\quad \mathrm{V} \quad \mathrm{O}$ 'Bright did not fetch water.'

(v) oche ju jkpa li John king give book to John S V DO IO 'The king gave a book to John.'

(v) oche je jkpa li John nǒ king give book to John Neg $\mathrm{S} \quad \mathrm{V}$ DO IO 'The king did not give a book to John.' 
(4) Constituent Negation: Affirmative/Negative Sentences in Idoma

a. xè̀nya lù moto

woman buy car

'The woman bought a car.'

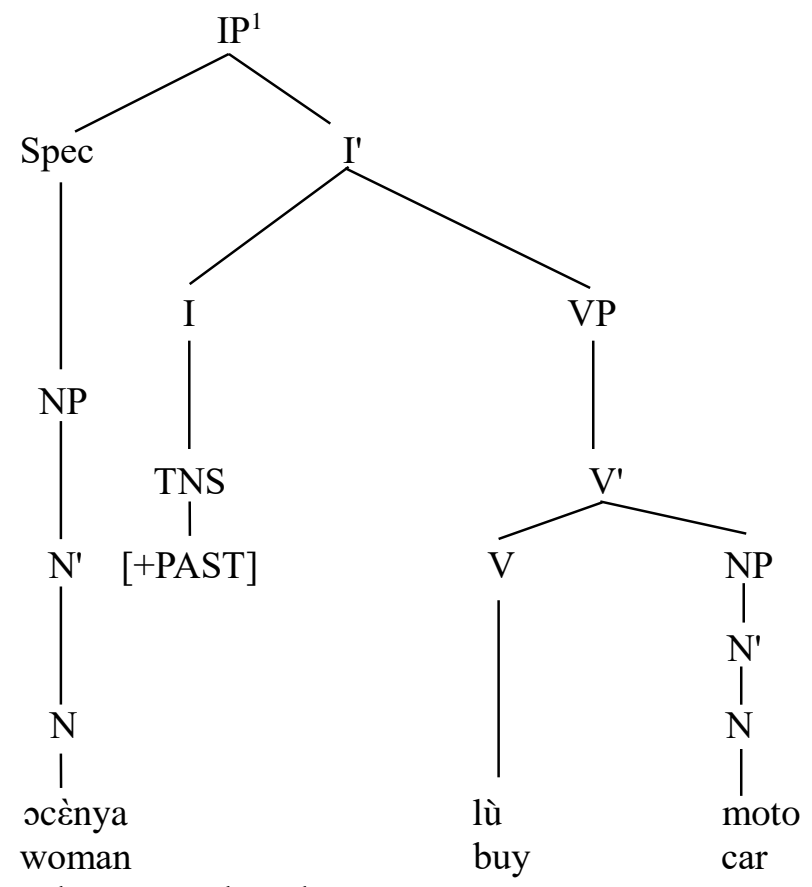

'The woman bought a car.'

${ }^{1}$ In the above tree diagram/phrase-marker, $\mathbf{I P}=$ Inflection Phrase; where $\mathbf{I}=$ head of the phrase. 
90 The Syntactic Position of Negative Markers in Idoma and Tiv:

b. ń túr bólu lo olè

1SG. played ball in house

'I played ball at home.'

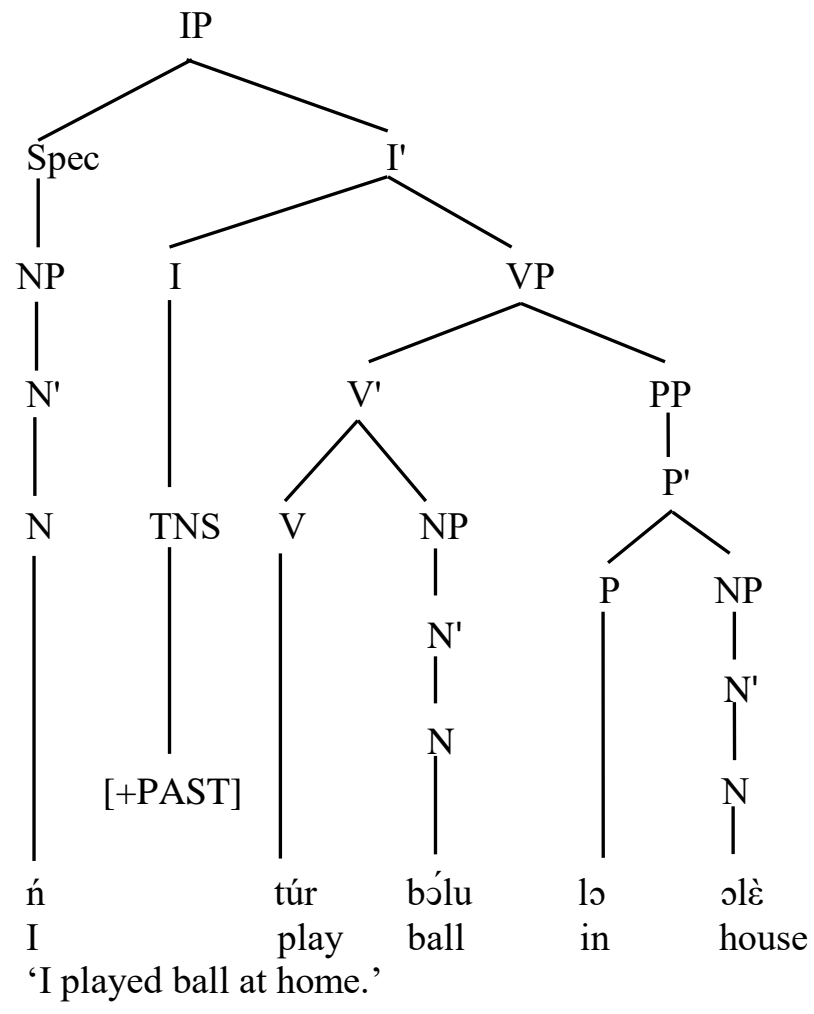

(5) Subject-NP Negation

j wj̀cenya lá moto nǒ

it woman bought car Neg

'It was not the woman that bought a car.' 
(6) Object-NP Negation:

$\mathrm{O}$ wé mótò lo jcenya lá nǒ

it is car that woman bought $\mathrm{Neg}$

'It was not car that the woman bought.'

\subsection{Negation in Tiv}

Negative constructions in Tiv language are similar to that of Idoma language. The negative marker occurs at the sentence final position. Therefore, the Tiv negative marker is placed post-verbally after the constituents. This can be exemplified with the data in (7) below:

(7) Sentence Negation: Affirmative/Negative Sentences in Tiv

a. Affirmative

(i) shèn òr u sule 1SG. am a farmer $\mathrm{S} \quad \mathrm{V} \quad \mathrm{O}$

'I am a farmer.'

(ii) Peter yá kwàghyan Peter eat food S V O

'Peter ate the food.' b. Negative

(i) shèn òr u sule ga 1SG. am a farmer Neg S $\quad \mathrm{O} \quad \mathrm{O}$

'I am not a farmer.'

(ii) Peter yá kwàghyan ga Peter eat food Neg $\mathrm{S} \quad \mathrm{V} \quad \mathrm{O}$ 'Peter did not eat the food.'

(iii) ngo jiedì chìnkafa mother cook rice S V O 'Mother cooked rice.'

(iii) ngo jiedì chìnkafa ga mother cook rice $\mathrm{Neg}$ S V O 'Mother did not cook rice.'

(iv) Bíntà késì mgerèm Binta fetch water S $\mathrm{V} \quad \mathrm{O}$

(iv) Binta kesi mgerem ga Binta fetch water Neg S V O 
92 The Syntactic Position of Negative Markers in Idoma and Tiv:

'Binta fetched water.' 'Binta did not fetch water.'

(v) Mímìe va

Mimie come

S V

'Mimie has come.' (v) Mimie ngwè va ga Mimie has come $\mathrm{Neg}$ S V

'Mimie has not come.'

(8) Constituent Negation: Affirmative Sentences in Tiv
a. kwásé lá yá-m mótò
woman the buy+PAST car
'The woman bought a car.'

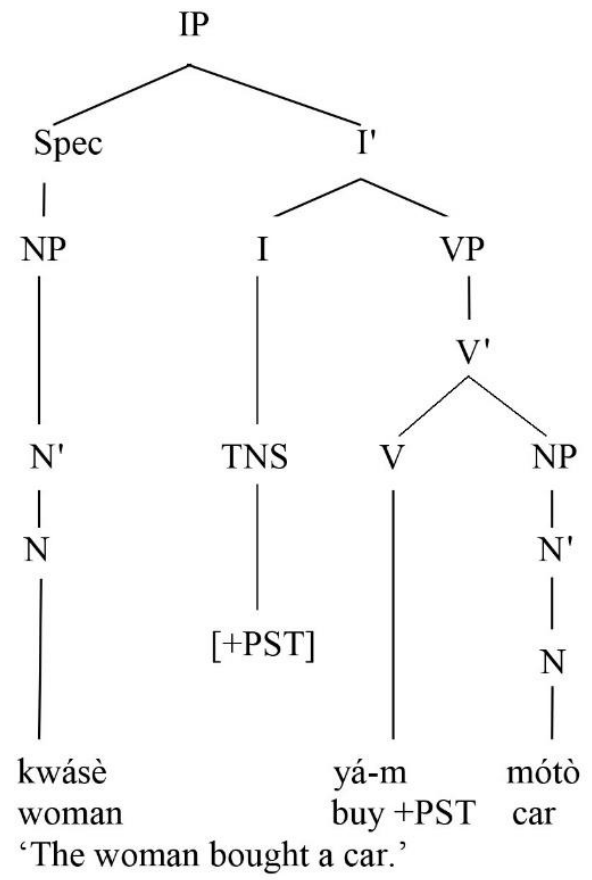


b. shèn gbidye bolu kén iyol I played ball in house

'I played ball at home.'

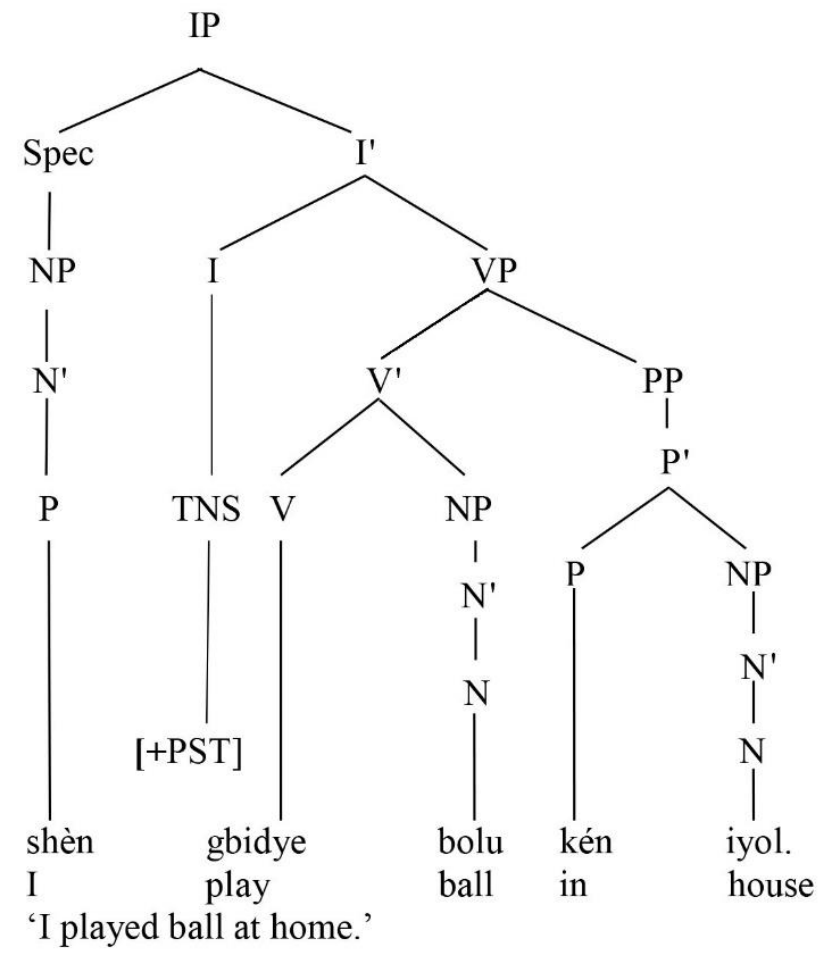


94 The Syntactic Position of Negative Markers in Idoma and Tiv:

(9) Subject-NP Negation

ká kwásè la yá-m mótò ga

it woman the bought car Neg

It was not the woman that bought a car.'

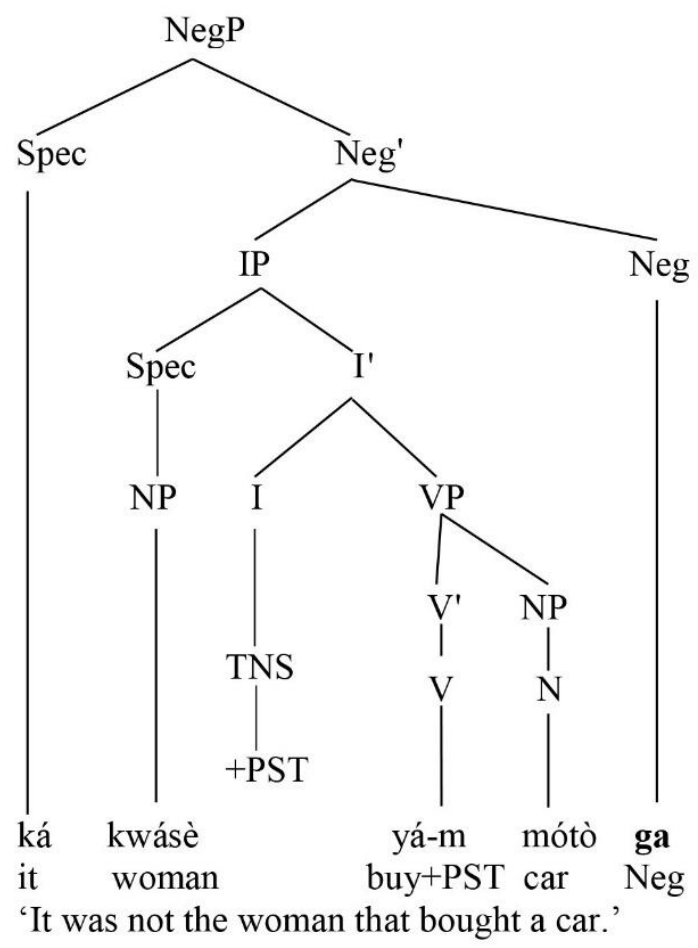


(10) Object-NP Negation

ká moto kwásè lá yá-m ga

it car woman the buy+PST Neg

'It was not car that the woman bought.'

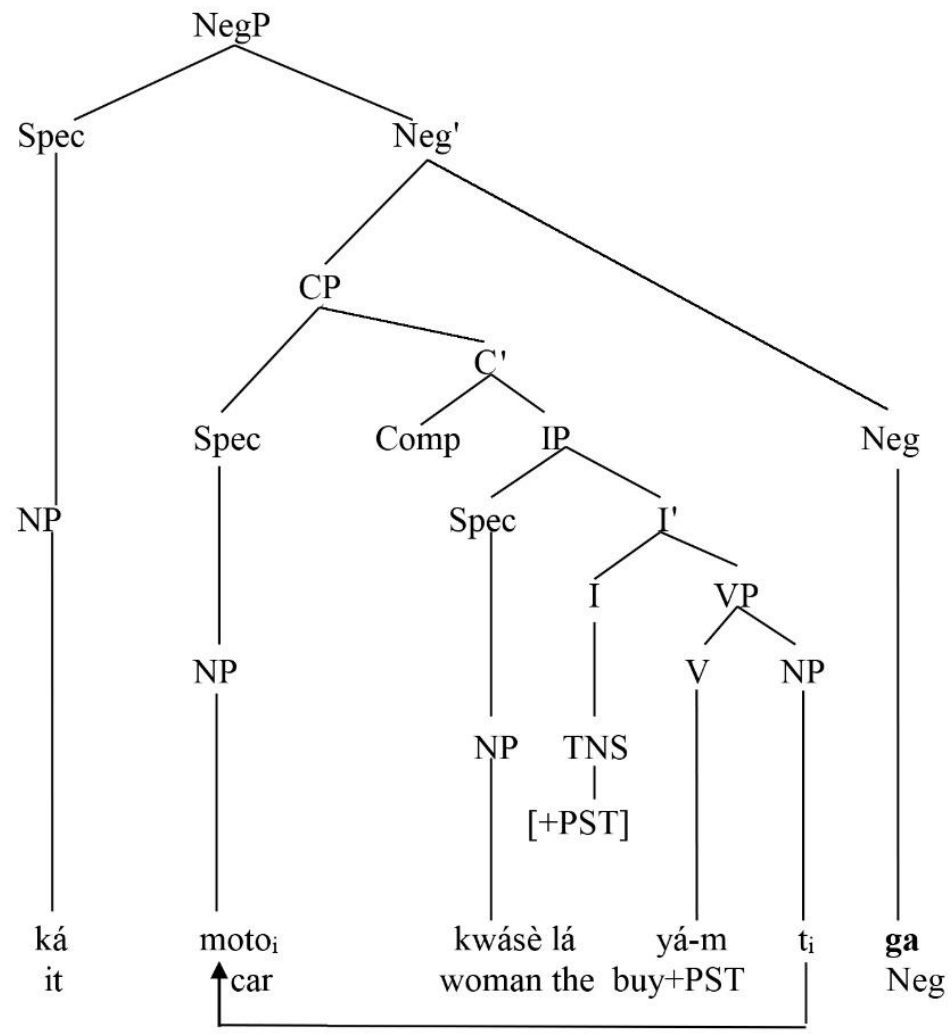

'It was not car that the woman bought.' 
96 The Syntactic Position of Negative Markers in Idoma and Tiv:

\section{Findings}

Based on copious and relevant empirical data, the present study has made the following discoveries about the syntax of negation in Idoma and Tiv languages:

(i) It was discovered that despite the fact that the two languages exhibit SVO word order, they do not conform to the hypothesis that negative markers in SVO languages occur before or immediately after the verb in a given grammatical sentence (Dryer 1988).

(ii) From the available data, it was also discovered that both Idoma and Tiv have their negative markers consistently occurring at the sentence-final position, in a given negative construction.

(iii) As evidence to corroborate the existing position in the literature, effort was made to present data from English and Yorùbá, as two SVO languages that conform to the Language Universal Validity, in terms of the syntactic position of negative markers.

\section{Conclusion}

In conclusion, the syntactic position of negative markers in both Idoma and Tiv languages has been properly examined with relevant, copious and illuminating data from the two languages. It was discovered that the negative markers in each of the two languages occur at the sentence-final position. In addition to the fact that Idoma and Tiv belong to the same language family (Benue-Congo), they show a high degree of similarities, in terms of the syntactic position of the negative markers. And they both make use of overt negative markers in all cases of negative constructions. Based on the available syntactic 
evidence in the present study, it is recommended that further researches could be carried out on other SVO languages, with the hope of finding out the extent to which such languages conform to the assumed language universals.

\section{References}

Akiga, B. 1965. Akiga's Story: The Tiv Tribe as Seen by One of Its Members. Translated and Annotated by Rupert East. London: OUP.

Armstrong, R. 1955. The Idoma-Speaking People. In D. Forde et al. (eds.), People of the Niger-Benue Confluence, Ethnographic Survey of Africa. London: International African Institute.

Atel, T. 2004. Dynamics of Tiv Religion and Culture: A PhilosophicalTheological Perspective. Lagos: Free Enterprise Publishers.

Blench, R. \& D. Mallam. 2004. The Benue-Congo Languages: A Proposed Internal Classification. Cambridge: CUP.

Cook, V. \& M. Newson. 2007. Chomsky's Universal Grammar: An Introduction. 3rd edition. Oxford: Blackwell Publishing.

Crystal, D. 2008. A Dictionary of Linguistics and Phonetics. 6th edition. Oxford: Blackwell Publishing.

Dryer, M. 1988. Universals of Negative Position. In M. Hammond et al. (eds.), Studies in Syntactic Typology. Amsterdam: John Benjamins.

Erim, E. 1981. Idoma Nationality 1600-1900: Problem in Studying the Origins and Development of Ethnicity. Enugu: Forth Dimension Publishing Company.

Gbor, J. 1978. Mdugh U Tiv Man Mnyer Ve Ken Benue. Zaria: Gaskiya. 
98 The Syntactic Position of Negative Markers in Idoma and Tiv:

Greenberg, J. 1966. Universals of Language. 2nd edition. London: MIT Press.

Haegeman, L. 1991. Introduction to Government and Binding Theory. Oxford: Blackwell Publishing.

Haegeman, L. 1995. The Syntax of Negation. New York: CUP.

Horrocks, G. 1987. Generative Grammar. New York: Longman.

Jackson, H. 2007. Key Terms in Linguistics. London: Continuum.

Jespersen, O. 1917. Negation in English and Other Languages. London: George Allen and Unwin.

Lyons, J. 1995. Linguistic Semantics: An Introduction. Cambridge: CUP.

Malmkjaer, K. (ed.). 2002. The Linguistics Encyclopedia. 2nd edition. London: Routledge.

Pericliev, V. 2018. Language Universals: Their Discovery and Verbalization by Machine. Journal of Universal Language 19.1, 33-35.

Sanusi, I. 2007. Diagnostics for Distinguishing between SVO \& SOV Languages: Evidence from English \& Batonu. In O. Ndimele (ed.), Nigeria Languages, Literatures, Culture \& Reforms: A Festchrisft for Ayo Bamgbose 613-620. Port Harcourt: M\&J Grand Orbit Communications.

Sanusi, I. 2017. Introducing the Linguist \& Linguistics. 2nd edition. Ibadan: University Press PLC.

Umaru, Y. 2016. The Syntax of Relative Clause Constructions in Idoma: A Government and Binding Approach. Unpublished Ph.D. Dissertation, Nasarawa State University.

Watter, J. 2000. Syntax. In B. Heine \& D. Nurse (eds.), African Languages: An Introduction. Cambridge: CUP. 